\title{
Diagnostic evaluation of qRT-PCR-based kit and dPCR-based kit for COVID-19
}

\author{
Cherl-Joon Lee ${ }^{1}$ Wonseok Shin ${ }^{2} \cdot$ Seyoung Mun ${ }^{3,4,5} \cdot$ Minjae Yu $^{5,6} \cdot$ Young-Bong Choi ${ }^{7}$. Dong Hee Kim ${ }^{8}$. \\ Kyudong $\operatorname{Han}^{1,2,4,5,6}$
}

Received: 15 August 2021 / Accepted: 1 September 2021 / Published online: 15 September 2021

(c) The Genetics Society of Korea 2021

\begin{abstract}
Background Coronavirus disease of 2019 (COVID-19) is well known as a fatal disease, first discovered at Wuhan in China, ranging from mild to death, such as shortness of breath and fever. Early diagnosis of COVID-19 is a crucial point in preventing global prevalence.

Objective We aimed to evaluate the diagnostic competency and efficiency with the Allplex ${ }^{\mathrm{TM}} 2019-\mathrm{nCoV}$ Assay kit and the Dr. PCR 20 K COVID-19 Detection kit, designed based on the qRT-PCR and dPCR technologies, respectively.

Methods A total of 30 negative and 20 COVID-19 positive specimens were assigned to the diagnostic test by using different COVID-19 diagnosis kits. Diagnostic accuracy was measured by statistical testing with sensitivity, specificity, and co-efficiency calculations.

Results Comparing both diagnostic kits, we confirmed that the diagnostic results of 30 negative and 20 positive cases were the same pre-diagnostic results. The diagnostic statistics test results were perfectly matched with value (1). Cohen's Kappa coefficient was demonstrated that the given kits in two different ways were "almost perfect" with value (1). In evaluating the detection capability, the dilutional linearity experiments substantiate that the Dr. PCR 20 K COVID-19 Detection kit could detect SARS-CoV-2 viral load at a concentration ten times lower than that of the Allplex ${ }^{\mathrm{TM}}$ 2019-nCoV Assay kit.

Conclusions In this study, we propose that the dPCR diagnosis using LOAA dPCR could be a powerful method for COVID19 point-of-care tests requiring immediate diagnosis in a limited time and space through the advantages of relatively low sample concentration and small equipment size compared to conventional qRT-PCR.
\end{abstract}

Keywords Coronavirus disease of 2019 - Severe Acute Respiratory Syndrome Coronavirus 2 - quantitative real-time PCR . Digital PCR

Cherl-Joon Lee and Wonseok Shin contributed equally to this work.

Dong Hee Kim

anedhkim@hanmail.net

$\triangle$ Kyudong Han

kyudong.han@gmail.com

1 Department of Bio-Convergence Engineering, Dankook University, Jukjeon 16890, Republic of Korea

2 NGS Clinical Laboratory, Dankook University Hospital, Cheonan 31116, Republic of Korea

3 Department of Nanobiomedical Science, Dankook University, Cheonan 31116, Republic of Korea

4 Center for Bio-Medical Engineering Core Facility, Dankook University, Cheonan 31116, Republic of Korea
5 DKU-Theragen institute for NGS analysis (DTiNa), Cheonan 31116, Republic of Korea

6 Department of Microbiology, College of Science and Technology, Dankook University, Cheonan 31116, Republic of Korea

7 Department of Chemistry, College of Science and Technology, Dankook University, Cheonan 31116, Republic of Korea

8 Department of Anesthesiology and Pain Management, Dankook University College of Medicine, Cheonan 31116, Republic of Korea 


\section{Introduction}

Coronavirus disease of 2019 (COVID-19) is a human respiratory infectious disease caused by a novel type of coronavirus (Severe acute respiratory syndrome coronavirus 2; SARSCoV-2) that was first reported in Wuhan, China, in December 2019 and has become a worldwide pandemic (Kumar et al. 2021; Zhang et al. 2020). As far as is known, SARS-CoV-2 spreads from an infected person to others through respiratory fluids and aerosols carrying the infectious virus. The rapid spread of the COVID-19 pandemic worldwide has been caused by misdiagnosis and asymptomatic transmission (Syal 2021). COVID-19 can cause mild symptoms ranging from loss of smell and taste, fever, muscle pain, and acute shortness of breath (Cascella et al. 2021; Garg et al. 2020). However, since senior citizens, immunocompromised patients, and patients with underlying diseases cause death in severe cases, accurate early diagnosis and comprehensive infectious disease prevention and control are required worldwide before developing of a COVID-19 therapeutic agent. Early diagnosis of COVID-19 is important because it helps determine the direction of treatment and can prevent several fatal complications at an early stage (Peck 2020).

There are several methods for COVID-19 diagnostics and detection, including cell culture and microscopy, radiology-based detection, nucleic acid amplification tests, quantitative real-time PCR (qRT-PCR), and immunoassaybased detection (Russo et al. 2020; Udugama et al. 2020). Among the methods mentioned above, the qRT-PCR and the immunoassay-based detection methods are predominantly used for COVID-19 diagnosis. First, the immunoassay-based detection method uses the point that when the SARS-CoV-2 enters the human body, it stimulates the adaptive immune system to generate antibodies. This method uses IgM, which is produced 7 days and peaks at 28 days after SARS-CoV-2 viral infection, and $\mathrm{IgG}$, which is generated 10 days and peaks at 49 days after SARS-CoV-2 viral infection (Padoan et al. 2020; Xu et al. 2020). The advantage of this method is that the result can be checked after approximately $10 \mathrm{~min}$, it is not expensive, and it can be checked quickly and easily confirmed with a single drop of blood. However, the limitations of the immunoassay-based detection method are: First, in the primary antibody test, it may be challenging to determine whether a SARS-CoV-2-positive individual is infected due to the lack of antibodies in the body. Second, even in SARS-CoV-2 - positive individuals, there are cases in which no antibody response or antibody levels cannot be maintained. Third, the low accuracy of this test (50-70\%) has been reported (Dhamad and Rhida 2020; Watson et al. 2020). On the other hand, the qRT-PCR is a method that can confirm in real time using specific primers and probes for a specific viral gene sequence capable of diagnosing
COVID-19. Currently, qRT-PCR is used as a gold standard in the COVID-19 diagnosis (Goudouris 2021; Huergo and Thanh 2021; Murphy and Bustin 2009). The reason is that SARS-CoV-2 detection shows very high sensitivity (98.2\%) and specificity (100\%), and quantitative analysis is straightforward (Chung et al. 2021). However, the qRTPCR method can only be used under laboratory condition because it requires the medium-sized equipment and various laboratory tools for pre-sample preparation operation (Gupta et al. 2021).

Recently, in the diagnosis of COVID-19, a dPCR analysis method that compensates for the weakness of qRT-PCR is emerging and difficulty in field diagnosis (Dong et al. 2021; Verhaegen et al. 2016). The dPCR method for diagnosing COVID-19 is similar to qRT-PCR by hybridizing specific primers and probes to specific viral gene sequences (Dang et al. 2020). Among the currently commercialized dPCR systems, Optolane's LOAA digital real-time PCR analyzer (LOAA dPCR, Optolane, Seongnam, Republic of Korea) released in 2020 integrates light source control and thermal control sensors to miniaturize the equipment, so that it takes less space than the qRT-PCR system. In addition, LOAA dPCR can monitor real-time amplification, and the target gene is placed in each well. Amplification and fluorescence analysis are performed simultaneously in each well, so the probability of false negatives by the experiment is low. Therefore, LOAA dPCR with a small size and high accuracy is expected to play a role as a point of care testing (POCT) device in the future.

Currently, reagent products approved for emergency use for COVID-19 diagnosis in Korea have been developed by Kogen Biotech, Seegene, Solgent, SD Biosensor, Biosewoom, and etc. (Garg et al. 2021; Park and Chung 2021; Sung et al. 2020). Among them, Allplex ${ }^{\mathrm{TM}} 2019-\mathrm{nCoV}$ Assay kit (Seegene, Seoul, Republic of Korea) is a qRTPCR-based COVID-19 diagnostic kit and has received the US Food and Drug Administration (FDA) Emergency Use Authorization (EUA) and the Korean Ministry of Food and Drug Safety (KMFDS) EUA approval (Lai et al. 2021). In the previous study, the Allplex ${ }^{\mathrm{TM}} 2019-\mathrm{nCoV}$ Assay kit (Seegene, Seoul, Republic of Korea) showed high performance in sensitivity as a result of confirming clinical performance by applying KCDC qRT-PCR protocol as a gold standard (Freire-Paspuel and Garcia-Bereguiain 2021). Therefore, currently in Korea, the Allplex ${ }^{\mathrm{TM}} 2019-\mathrm{nCoV}$ Assay kit (Seegene, Seoul, Republic of Korea) is typically used for the COVID-19 diagnosis. However, since this assay is a qRT-PCR-based method, it has disadvantages such as space limitation, relatively high qPCR equipment cost, and relatively long experimental time. In order to overcome these shortcomings, Optolane Co., Ltd. launched the LOAA dPCR assay (Optolane, Seongnam, Republic of Korea) in 2020, 
a compact and relatively short test time. In particular, the semiconductor chip-based Dr. PCR 20 K COVID-19 detection kit (Optolane, Seongnam, Republic of Korea) is the first dPCR-based COVID-19 diagnostic kit developed in Korea. In addition, this kit was approved for COVID-19 diagnostic reagent from the Korea Ministry of Food and Drug Safety (MFDS) on May 18, 2020.

Here, we performed qRT-PCR with the Allplex ${ }^{\mathrm{TM}}$ Assay kit currently used as a gold standard and APCR with the Dr. PCR 20 K COVID-19 Detection kit using actual COVID-19 patient samples, respectively. In addition, based on the results derived from each method, the effectiveness of COVDI-19 diagnosis was evaluated and comparatively analyzed.

\section{Materials and methods}

\section{Collection clinical specimens}

The Korean government has sufficiently secured and supported various types of COVID-19 samples, including respiratory and blood, from a total of six medical institutions with proven clinical evaluation capabilities. Here, we obtained a total of 50 specimens, of which were derived from 38 pharyngeal swabs (upper respiratory samples) and 12 sputa (lower respiratory samples) from Seoul Clinical Laboratories (SCL, Yongin, Republic of Korea) among those institutions. The specimens obtained are the residual samples from 20 positive and 30 negative specimens diagnosed with COVID-19 at the SCL medical institution. All specimens were stored in $3 \mathrm{~mL}$ of viral transport media (Cat. No UTNFS-3B-1, Noble Biosciences, Inc., Hwaseong, Republic of Korea). This study was performed in accordance with the Declaration of Helsinki and the International Conference on Harmonization Good Clinical Practice guidelines and approved by relevant regulatory from SCL Institutional Review Board (IRB-20-008). All specimen donors submitted written consent before they participated in the study.

\section{Viral RNA isolation}

In a total of 50 specimens, viral RNAs were isolated from 38 pharyngeal swabs using each $200 \mu \mathrm{L}$ of a viral transport media with the KingFisher Flex system (ThermoFisher Scientific Inc., Worcester, MA, USA), an automated nucleic acid extraction system, following the manufacturer's guidelines protocol (Lin et al. 2021). In addition, we isolated viral RNAs using the Advansure ${ }^{\mathrm{TM}} \mathrm{E} 3$ system (LG Chem, Ltd., Seoul, Korea), an automated nucleic acid extraction system, and $200 \mu \mathrm{L}$ each of 12 viral transport media obtained from sputum specimens according to the manufacturer's guideline (Lee et al. 2021). The viral RNAs isolated by each system were dissolved in $50 \mu \mathrm{L}$ of RNasefree water. Then, the eluted samples were stored at -80 ${ }^{\circ} \mathrm{C}$ in a deep freezer.

\section{qRT-PCR assay with Allplex ${ }^{\mathrm{TM}}$ 2019-nCoV Assay kit}

We carried out qRT-PCR using the stored RNA samples from the 50 specimens to evaluate the COVID-19 detection capability of Allplex ${ }^{\mathrm{TM}} 2019-\mathrm{nCoV}$ Assay kit (Cat. No RP10250X, Seegene, Seoul, Republic of Korea). The qRTPCR assay was performed according to the protocol of the manufacturer (Fig. 1). The Allplex ${ }^{\mathrm{TM}}$ 2019-nCoV Assay kit includes primer sets and probes targeting the RdRp, E and $\mathrm{N}$ genes of SARS-CoV-2 (Ambrosi et al. 2021). The target viral genes amplification was performed by following process: cDNA synthesis step of $20 \mathrm{~min}$ at $50{ }^{\circ} \mathrm{C}$, predenaturation step of $15 \mathrm{~min}$ at $95^{\circ} \mathrm{C}$, followed by 45 cycles of denaturation step $15 \mathrm{~s}$ at $94{ }^{\circ} \mathrm{C}, 30 \mathrm{~s}$ at $58^{\circ} \mathrm{C}$ for annealing and extension steps. CFX96 ${ }^{\mathrm{TM}}$ Real-Time PCR Detection System (Bio-Rad, Hercules, CA, USA) was used for qRTPCR assay.

\section{dPCR assay with Dr. PCR 20 K COVID-19 detection kit}

dPCR systems is divided into droplet type and separation type according to the method of dispensing the samples (Fig. 2) (Cao et al. 2017). Among them, the LOAA dPCR system (Optolane, Seongnam, Republic of Korea) released in 2020 is a separation type dPCR equipment. To evaluate the COVID-19 detection capability of Dr. PCR $20 \mathrm{~K}$ COVID-19 Detection kit (Cat no. DCM402-X, Optolane, Seongnam, Republic of Korea), we performed LOAA dPCR assay using the same 50 viral RNAs that we carried out qRT-PCR analysis on. The dPCR assay with Dr. PCR $20 \mathrm{~K}$ COVID-19 Detection kit was performed following to the manufacture's protocol (Fig. 1). Dr. PCR 20 K COVID-19 Detection kit includes primer sets and probes that is targeting the RdRp and E genes of SARS-CoV-2. The target viral genes amplification was conducted by following process: cDNA synthesis step of $10 \mathrm{~min}$ at $50{ }^{\circ} \mathrm{C}$, pre-denaturation step of 10 min at $95{ }^{\circ} \mathrm{C}$, followed by 45 cycles of denaturation step $10 \mathrm{~s}$ at $95{ }^{\circ} \mathrm{C}, 60 \mathrm{~s}$ at $60{ }^{\circ} \mathrm{C}$ for annealing \& extension step.

\section{Data analysis}

The qRT-PCR-based Allplex ${ }^{\mathrm{TM}}$ 2019-nCoV Assay kit results were measured as $\mathrm{Ct}$ values and dPCR-based Dr. PCR 20 K COVID-19 Detection kit results were measured as $\mathrm{C} / \mu \mathrm{L}$ values. The $\mathrm{Ct}$ values of the Allplex ${ }^{\mathrm{TM}} 2019$ nCoV Assay kit results were automatically determined for a diagnosis of COVID-19 using the Seegene Viewer 
(A)

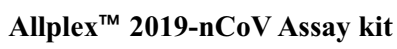

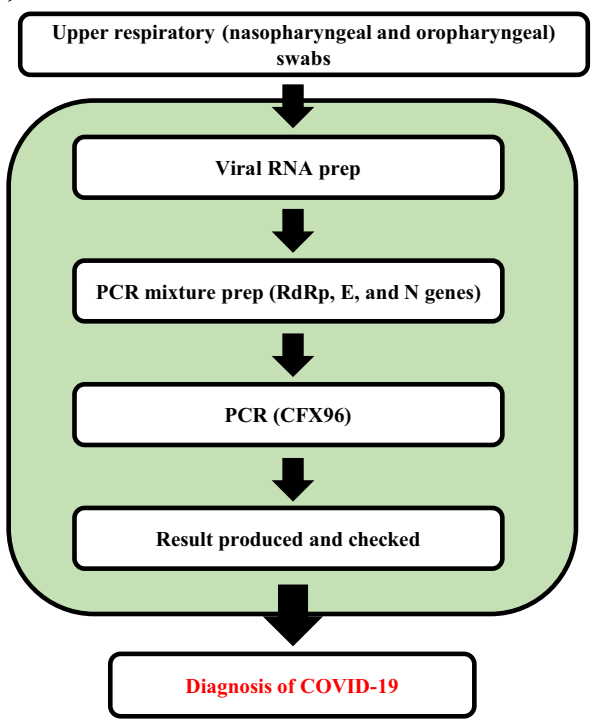

Fig. 1 The workflow of COVID-19 diagnosis using Allplex ${ }^{\text {TM }}$ 2019nCoV Assay and Dr. PCR 20 K COVID-19 Detection platform. A The Allplex ${ }^{\text {TM }}$ 2019-nCoV Assay kit is a qRT-PCR-based method for COVID-19 detection that is diagnosed using the RdRp gene, E

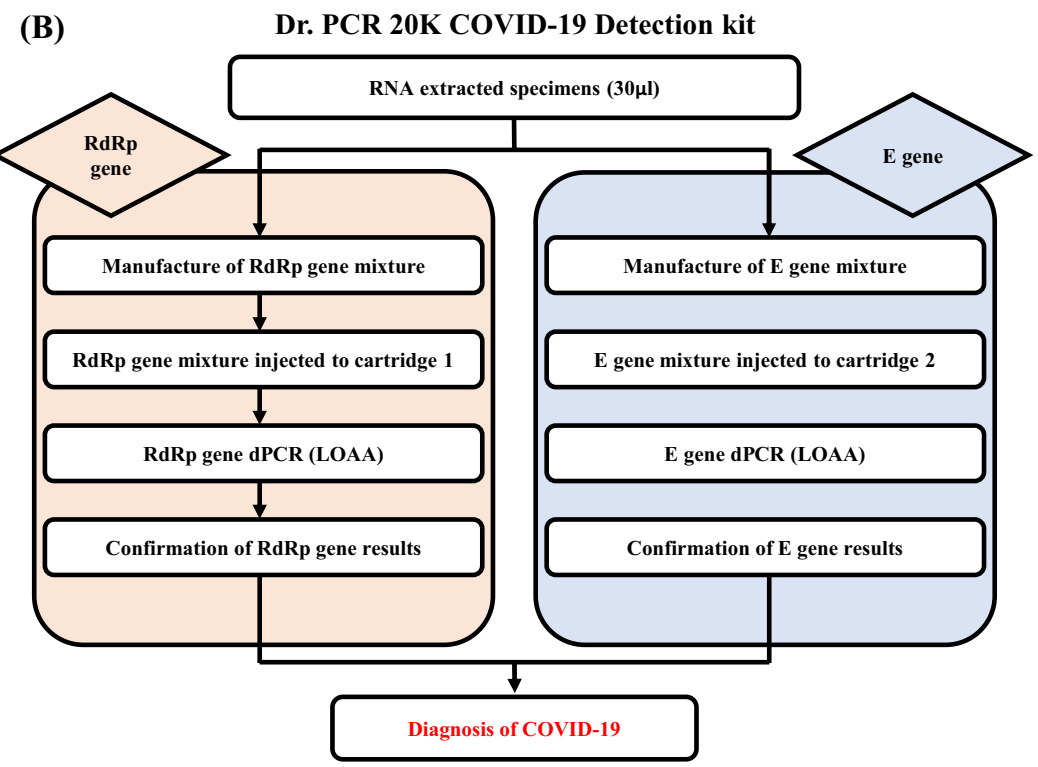

gene and N gene of SARS-CoV-2. B The Dr. PCR 20 K COVID-19 Detection kit is a dPCR-based product that diagnoses COVID-19 using the RdRp and E genes of the SARS-CoV-2
(A)

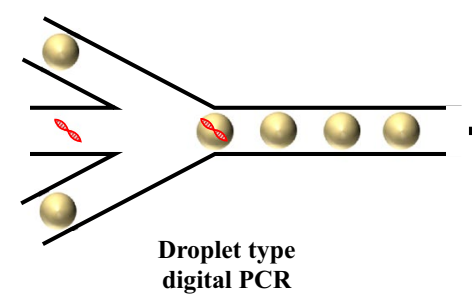

(B)

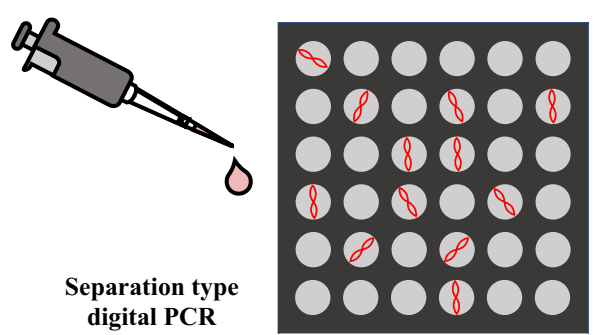

(C)

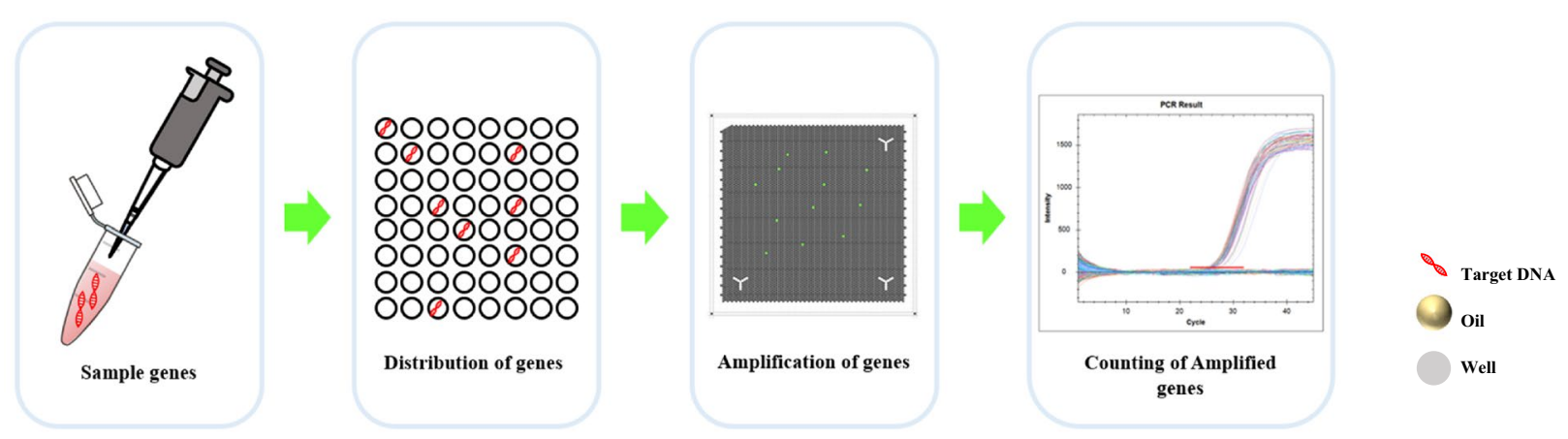

Fig. 2 Schematic diagram of the digital PCR assay. A In the droplet type APCR method, the red and yellow molecules represent target DNA and droplet oil, respectively. B In the separation type digital
PCR method, the gray circles represent the wells already divided in a semiconductive chip. C The workflow of the LOAA digital PCR assay 
2019-nCoV software v1 (Freppel et al. 2020). The C/ $\mu \mathrm{L}$ values of Dr. PCR 20 K COVID-19 detection kit results were automatically determined by LOAA Dr. PCR software 3.0.0 as a diagnosis of COVID-19. We calculated the COVID-19 diagnosis agreement of both kits using Cohen's Kappa analysis (Daly et al. 2019; Inaba et al. 2021). Kappa $(K)$ value is interpreted as poor $(K<0.00)$, slight $(0.00<K<0.20)$, fair $(0.20<K<0.40)$, moderate $(0.41<K<0.60)$, substantial $(0.61<K<0.80)$, and almost perfect $(0.81<K<1.00)$. In addition, we performed the dilutional linearity experiments by spike-in the high concentration of COVID-19 positive sample (Ct value near 10) to the negative sample to compare the detection capability according to the dilution factor $\left(10^{-1}\right.$ to $\left.10^{-10}\right)$ of two kits (Kim et al. 2021).

\section{Results and discussion}

\section{Evaluating COVID-19 diagnosis with the Allplex ${ }^{\mathrm{TM}}$ 2019-nCoV Assay kit}

We selected the most popular qRT-PCR-based Allplex ${ }^{\mathrm{TM}}$ 2019-nCoV Assay kit in Korea to evaluate the efficiency of COVID-19 diagnosis. In addition, pharyngeal swab or sputum samples from 20 COVID-19 positive patients and 30 normal individuals (i.e., COVID-19 negative) were obtained from Seoul Clinical Laboratories (Gyeonggi, Republic of Korea) (Supplementary Table S1). The COVID-19 diagnosis result using the Allplex ${ }^{\mathrm{TM}}$ 2019nCoV Assay kit is evaluated by the Ct value of qRT-PCR. As shown in Table 1, the potential outcome types of this kit are reported for a total of 9 CASE types (CASE-1 to -9) (Seegene 2021). When the Ct value of each internal control (IC), E gene, RdRp gene, or $\mathrm{N}$ gene is $\leq 40$, it is indicated as "Detected" $(+)$, and when it is $>40$ or not applicable (N/A), it is indicated as "Not detected" $(-)$. Depending on the (+) or (-) result of each gene, CASE-1 to -6 are determined to be "2019-nCoV positive" (Table 1). In the case of CASE-7, if IC is (+/-), E gene is $(+)$, and $\mathrm{RdRp}$ gene and $\mathrm{N}$ gene are $(-)$ determined as "Presumptive positive for 2019-nCoV", and re-experiment is required. If the IC is $(+)$ and all viral genes are (-) in the sample, it is determined as "Negative" (CASE-8). Samples with all (-) results for IC (HEX) and all viral genes are determined as "Invalid" (CASE-9) (Supplementary information).

As a result of performing a COVID-19 diagnostic test using the qRT-PCR-based Allplex ${ }^{\text {TM }}$ 2019-nCoV Assay kit with a total of 50 individual specimens, all ODP1 to ODP30 specimens extracted from normal individuals not infected with COVID-19 were "negative". In addition, all ODP31 to ODP50 specimens extracted from patients diagnosed with COVID-19 obtained "2019-nCoV positive" results (Table 2). Therefore, in the diagnostic evaluation of COVID-19 using the Allplex ${ }^{\mathrm{TM}}$ 2019-nCoV Assay kit, the false-negative and false-positive rates were 0 . In addition, the diagnostic sensitivity and specificity were 1 (van Stralen et al. 2009). Although we obtained results with a relatively small number of specimens, we confirmed that the qRT-PCR assay showed very high sensitivity and specificity using the Allplex ${ }^{\mathrm{TM}}$ 2019-nCoV Assay kit (Supplementary Table S2).
Table 1 Result interpretation of qRT-PCR with Allplex ${ }^{\text {TM }}$ 2019nCoV Assay kit

\begin{tabular}{|c|c|c|c|c|c|}
\hline Potential result type & $\begin{array}{l}\text { Internal } \\
\text { control }^{\dagger} \text { (HEX } \\
\text { dye) }\end{array}$ & $\begin{array}{l}\text { E gene } \\
\text { (FAM } \\
\text { dye) }\end{array}$ & $\begin{array}{l}\text { RdRp gene } \\
\text { (CalRed } 610 \\
\text { dye) }\end{array}$ & $\begin{array}{l}\text { N gene (Qua- } \\
\text { sar } 670 \text { dye) }\end{array}$ & Auto-interpretation \\
\hline CASE 1 & $+/-$ & + & + & + & 2019-nCoV positive \\
\hline CASE 2 & $+/-$ & + & - & + & 2019-nCoV positive \\
\hline CASE 3 & $+/-$ & + & + & - & \\
\hline CASE 4 & $+/-$ & - & + & + & \\
\hline CASE 5 & $+/-$ & - & - & + & \\
\hline CASE 6 & $+/-$ & - & + & - & \\
\hline CASE 7 & $+/-$ & + & - & - & $\begin{array}{l}\text { Presumptive } \\
\text { positive for 2019- } \\
\text { nCoV }\end{array}$ \\
\hline CASE 8 & + & - & - & - & Negative \\
\hline CASE 9 & - & - & - & - & Invalid \\
\hline
\end{tabular}

†This internal control (IC) material verifies all steps of the analysis process, including sample extraction, reverse transcription and PCR to demonstrate proper specimen processing and test validity of each specimen 
Table 2 Result interpretation of dPCR with Dr. PCR 20 K COVID-19 detection kit

\begin{tabular}{|c|c|c|c|c|c|c|c|c|c|c|}
\hline Sample no. & Sample type & E gene & $\mathrm{C}(\mathrm{t})$ & RdRp gene & $\mathrm{C}(\mathrm{t})$ & $\mathrm{N}$ gene & $\mathrm{C}(\mathrm{t})$ & $\begin{array}{l}\text { Internal } \\
\text { control (IC) }\end{array}$ & $\mathrm{C}(\mathrm{t})$ & Automatic analysis \\
\hline ODP01 & Pharyngeal Swab & - & N/A & - & N/A & - & N/A & + & 23.54 & Negative \\
\hline ODP02 & Pharyngeal Swab & - & N/A & - & N/A & - & N/A & + & 22.55 & Negative \\
\hline ODP03 & Pharyngeal Swab & - & N/A & - & N/A & - & N/A & + & 22.57 & Negative \\
\hline ODP04 & Pharyngeal Swab & - & N/A & - & N/A & - & N/A & + & 22.2 & Negative \\
\hline ODP05 & Pharyngeal Swab & - & N/A & - & N/A & - & N/A & + & 23.65 & Negative \\
\hline ODP06 & Pharyngeal Swab & - & N/A & - & N/A & - & N/A & + & 22.45 & Negative \\
\hline ODP07 & Pharyngeal Swab & - & N/A & - & N/A & - & N/A & + & 22.47 & Negative \\
\hline ODP08 & Pharyngeal Swab & - & N/A & - & N/A & - & N/A & + & 22.2 & Negative \\
\hline ODP09 & Pharyngeal Swab & - & N/A & - & N/A & - & N/A & + & 23.6 & Negative \\
\hline ODP10 & Pharyngeal Swab & - & N/A & - & N/A & - & N/A & + & 22.41 & Negative \\
\hline ODP11 & Pharyngeal Swab & - & N/A & - & N/A & - & N/A & + & 22.28 & Negative \\
\hline ODP12 & Pharyngeal Swab & - & N/A & - & N/A & - & N/A & + & 22.03 & Negative \\
\hline ODP13 & Pharyngeal Swab & - & N/A & - & N/A & - & N/A & + & 22.32 & Negative \\
\hline ODP14 & Pharyngeal Swab & - & N/A & - & N/A & - & N/A & + & 23.54 & Negative \\
\hline ODP15 & Pharyngeal Swab & - & N/A & - & N/A & - & N/A & + & 23.98 & Negative \\
\hline ODP16 & Pharyngeal Swab & - & N/A & - & N/A & - & N/A & + & 23.16 & Negative \\
\hline ODP17 & Pharyngeal Swab & - & N/A & - & N/A & - & N/A & + & 22.2 & Negative \\
\hline ODP18 & Pharyngeal Swab & - & N/A & - & N/A & - & N/A & + & 22.11 & Negative \\
\hline ODP19 & Pharyngeal Swab & - & N/A & - & N/A & - & N/A & + & 22.74 & Negative \\
\hline ODP20 & Pharyngeal Swab & - & N/A & - & N/A & - & N/A & + & 22.84 & Negative \\
\hline ODP21 & Pharyngeal Swab & - & N/A & - & N/A & - & N/A & + & 22.16 & Negative \\
\hline ODP22 & Pharyngeal Swab & - & N/A & - & N/A & - & N/A & + & 22.23 & Negative \\
\hline ODP23 & Pharyngeal Swab & - & N/A & - & N/A & - & N/A & + & 22.27 & Negative \\
\hline ODP24 & Pharyngeal Swab & - & N/A & - & N/A & - & N/A & + & 22.87 & Negative \\
\hline ODP25 & Pharyngeal Swab & - & N/A & - & N/A & - & N/A & + & 22.89 & Negative \\
\hline ODP26 & Pharyngeal Swab & - & N/A & - & N/A & - & N/A & + & 22.04 & Negative \\
\hline ODP27 & Pharyngeal Swab & - & N/A & - & N/A & - & N/A & + & 22.72 & Negative \\
\hline ODP28 & Pharyngeal Swab & - & N/A & - & N/A & - & N/A & + & 23.95 & Negative \\
\hline ODP29 & Pharyngeal Swab & - & N/A & - & N/A & - & N/A & + & 22.96 & Negative \\
\hline ODP30 & Sputum & - & N/A & - & N/A & - & N/A & + & 21.96 & Negative \\
\hline ODP31 & Pharyngeal Swab & + & 27.9 & + & 29.11 & + & 28.74 & + & 27.26 & 2019-nCoV detected \\
\hline ODP32 & Pharyngeal Swab & + & 20.87 & + & 22.42 & + & 23.29 & + & 39.93 & 2019-nCoV detected \\
\hline ODP33 & Pharyngeal Swab & + & 22.2 & + & 23.93 & + & 24.63 & + & 27.96 & 2019-nCoV detected \\
\hline ODP34 & Pharyngeal Swab & + & 25.62 & + & 27.54 & + & 27.85 & + & 26.78 & 2019-nCoV detected \\
\hline ODP35 & Pharyngeal Swab & + & 25.36 & + & 27.18 & + & 26.65 & + & 32.34 & 2019-nCoV detected \\
\hline ODP36 & Pharyngeal Swab & + & 27.14 & + & 28.21 & + & 28.86 & + & 26.87 & 2019-nCoV detected \\
\hline ODP37 & Pharyngeal Swab & + & 29.32 & + & 30.16 & + & 30.69 & + & 26.82 & 2019-nCoV detected \\
\hline ODP38 & Pharyngeal Swab & + & 24.76 & + & 26.27 & + & 26.71 & + & 27.34 & 2019-nCoV detected \\
\hline ODP39 & Pharyngeal Swab & + & 23.84 & + & 25.08 & + & 25.35 & + & 26.19 & 2019-nCoV detected \\
\hline ODP40 & Sputum & + & 27.3 & + & 28.71 & + & 28.25 & + & 29.1 & 2019-nCoV detected \\
\hline ODP41 & Sputum & + & 29.99 & + & 30.06 & + & 30.12 & + & 29.16 & 2019-nCoV detected \\
\hline ODP42 & Sputum & + & 25.68 & + & 26.91 & + & 27.25 & + & 27.55 & 2019-nCoV detected \\
\hline ODP43 & Sputum & + & 27.42 & + & 29.36 & + & 28.91 & + & 28.34 & 2019-nCoV detected \\
\hline ODP44 & Sputum & + & 28.64 & + & 28.98 & + & 29.51 & + & 28.23 & 2019-nCoV detected \\
\hline ODP45 & Sputum & + & 23.39 & + & 24.33 & + & 25.57 & + & 29.17 & 2019-nCoV detected \\
\hline ODP46 & Sputum & + & 23.06 & + & 24.29 & + & 24.55 & + & 28.2 & 2019-nCoV detected \\
\hline ODP47 & Sputum & + & 24.82 & + & 27.48 & + & 26.57 & - & N/A & 2019-nCoV detected \\
\hline ODP48 & Sputum & + & 27.78 & + & 29.97 & + & 29 & + & 27.91 & 2019-nCoV detected \\
\hline ODP49 & Sputum & + & 25.64 & + & 28 & + & 27.66 & + & 30.04 & 2019-nCoV detected \\
\hline
\end{tabular}


Table 2 (continued)

\begin{tabular}{lllllllllll}
\hline Sample no. & Sample type & E gene & $\mathrm{C}(\mathrm{t})$ & RdRp gene & $\mathrm{C}(\mathrm{t})$ & $\mathrm{N}$ gene & $\mathrm{C}(\mathrm{t})$ & $\begin{array}{l}\text { Internal } \\
\text { control (IC) }\end{array}$ & $\mathrm{C}(\mathrm{t})$ & Automatic analysis \\
\hline ODP50 & Sputum & + & 26.46 & + & 29.37 & + & 28.06 & - & N/A & 2019-nCoV detected \\
\hline
\end{tabular}

Table 3 Result interpretation of dPCR with Dr. PCR $20 \mathrm{~K}$ COVID-19 detection kit

\begin{tabular}{|c|c|c|c|c|c|}
\hline \multirow[t]{3}{*}{ Type } & \multirow[t]{3}{*}{ Valid well } & \multicolumn{2}{|c|}{ Green channel result } & \multirow[b]{3}{*}{$\begin{array}{l}\text { PCR control } \\
\text { (PCRC) }^{\S} \text { (Cy5 } \\
\text { dye) }\end{array}$} & \multirow[t]{3}{*}{ Result } \\
\hline & & \multicolumn{2}{|c|}{ SARS-CoV-2 } & & \\
\hline & & $\begin{array}{l}\text { RdRp gene } \\
\text { (FAM dye) }\end{array}$ & E gene (FAM dye) & & \\
\hline Positive control & $\geq 10,000$ & $\geq 0.257$ & $\geq 0.24$ & $\geq 1$ & Valid \\
\hline Negative control & & $<0.257$ & $<0.24$ & $\geq 1$ & Valid \\
\hline CASE 1 & & $\geq 0.257$ & $\geq 0.24$ & $\geq 1$ & COVID-19 positive \\
\hline CASE 2 & & $\geq 0.257$ & $<0.24$ & $\geq 1$ & Undetermined $^{\dagger}$ \\
\hline CASE 3 & & $<0.257$ & $<0.24$ & $\geq 1$ & COVID-19 negative \\
\hline CASE 4 & & $<0.257$ & $<0.24$ & $<1$ & Invalid $^{\ddagger}$ \\
\hline CASE 5 & $<10,000$ & - & - & - & Invalid* \\
\hline
\end{tabular}

*The change of the pattern of the whole well is confirmed and if the normal well is less than full, the experiment result for Digital PCR is not effective in the whole, so it is retested with a new cartridge after discarding the cartridge.

${ }^{\S}$ Determination of nucleic acid amplification of each tube according to PCR reaction and determination of inhibition of PCR reaction by specimen.

${ }^{\dagger}$ If E gene (beta coronavirus identification) is negative or RdRp gene (for new corona virus identification) is positive, it should be determined as undetermined.

¥The validity of the NTC and PC is determined based on the range defined by the manufacturer based on each $\mathrm{C} / \mathrm{uL}$ number when the PCRC 'Valid' condition is satisfied.

\section{Evaluating COVID-19 diagnosis with the Dr. PCR $20 \mathrm{~K}$ COVID-19 detection kit}

We performed a COVID-19 diagnostic test using the LOAA dPCR (Optolane, Seongnam, Republic of Korea) equipment and the Dr. PCR 20 K COVD-19 Detection kit (Optolane, Seongnam, Republic of Korea) with the same samples evaluated above. As shown in Table 3, LOAA dPCR assay results are reported as CASE-1 to -5 . To determine the diagnostic test efficacy, dPCR assay was performed using non-template control (NTC), positive control (PC), and PCR control (PCRC), respectively. The PC is composed of when RdRp gene and $\mathrm{E}$ gene. A valid decision can only be made when the number of valid wells is greater than 10,000 . The experiment is valid when RdRp gene (FAM dye) has a value of $\geq 0.257 \mathrm{C} / \mu \mathrm{L}, \mathrm{E}$ gene (FAM dye) $\geq 0.24 \mathrm{C} / \mu \mathrm{L}$, and PCRC has a value of $\geq 1 \mathrm{C} / \mu \mathrm{L}$ (Table 3 ).

As a result of the dPCR assay using the Dr. PCR $20 \mathrm{~K}$ COVD-19 Detection kit, 30 out of a total of 50 specimens obtained SARS-CoV-2 negative results, and 20 specimens obtained SARS-CoV-2 positive results (Table 4). Similar to the Allplex TM 2019-nCoV Assay kit, the ODP1 to ODP30 specimens were extracted from normal individuals not infected with COVID-19, and all of the SARS-CoV-2 negative results were obtained. In addition, the ODP31 to ODP50 specimens were samples extracted from patients diagnosed with COVID-19, and all of them obtained SARS$\mathrm{CoV}-2$ positive results. Therefore, in the diagnostic evaluation of COVID-19 using the dPCR assay with Dr. PCR $20 \mathrm{~K}$ COVD-19 Detection kit, the false-negative and false-positive rates were 0 . In addition, the diagnostic sensitivity and specificity were 1 (Supplementary Table S2).

\section{Comparison of detection evaluation for COVID-19 between Allplex ${ }^{\mathrm{TM}}$ 2019-nCoV Assay kit and Dr. PCR 20 K COVID-19 detection kit}

Comparison of diagnostic results between qRT-PCR-based Allplex ${ }^{\mathrm{TM}}$ 2019-nCoV Assay kit and dPCR-based Dr. PCR 20 K COVD-19 Detection kit showed the same results (Supplementary Table S3). Cohen's Kappa coefficient was tested to measure the reliability and agreement between the two results (Czodrowski 2014). The Kappa Coefficient has a value between 0 and 1 , and the closer to 1 , the more consistent the data to be compared. Therefore, when the detection results of the Allplex ${ }^{\mathrm{TM}}$ 2019-nCoV Assay kit and the Dr. PCR 20 K COVID-19 Detection kit were confirmed with 


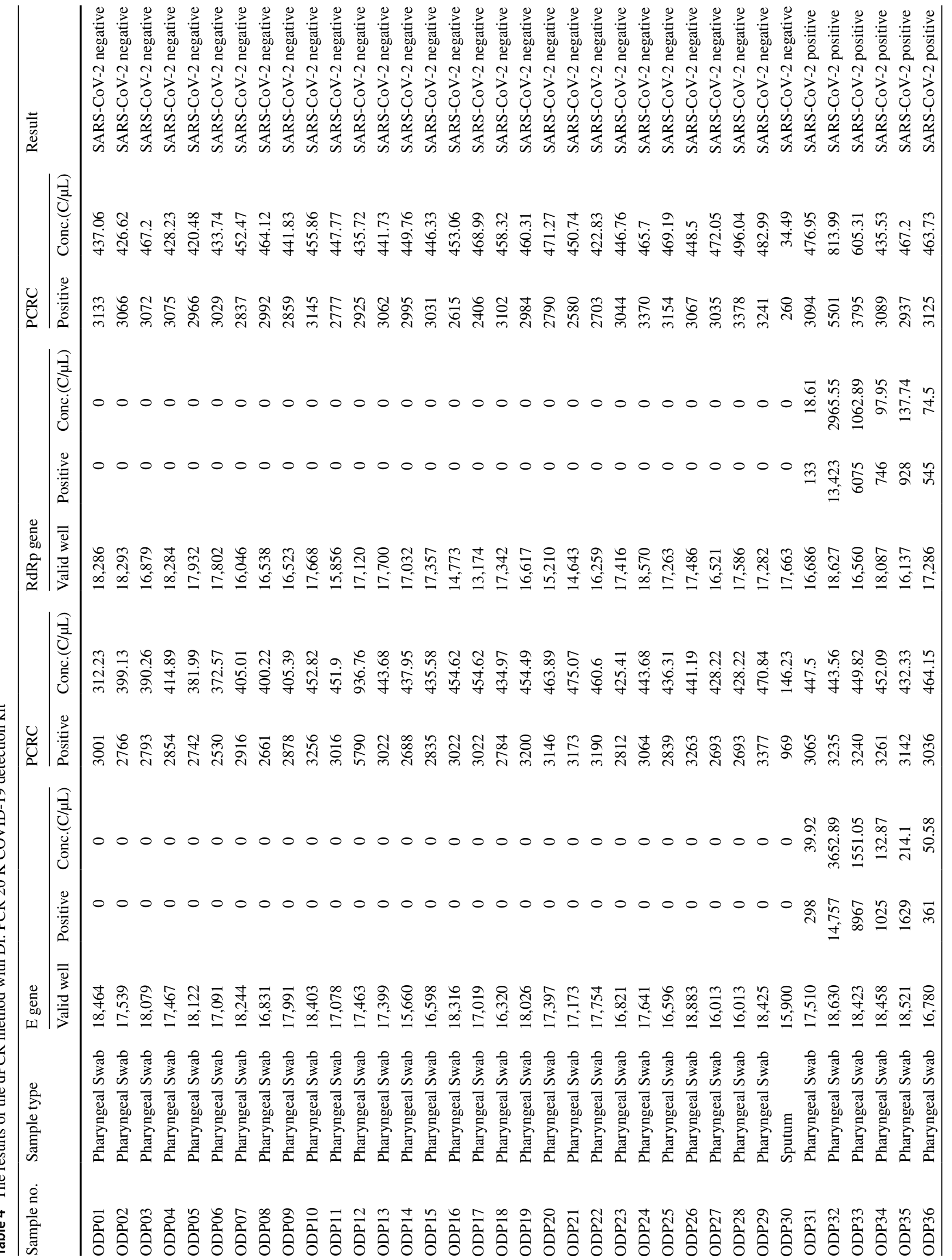




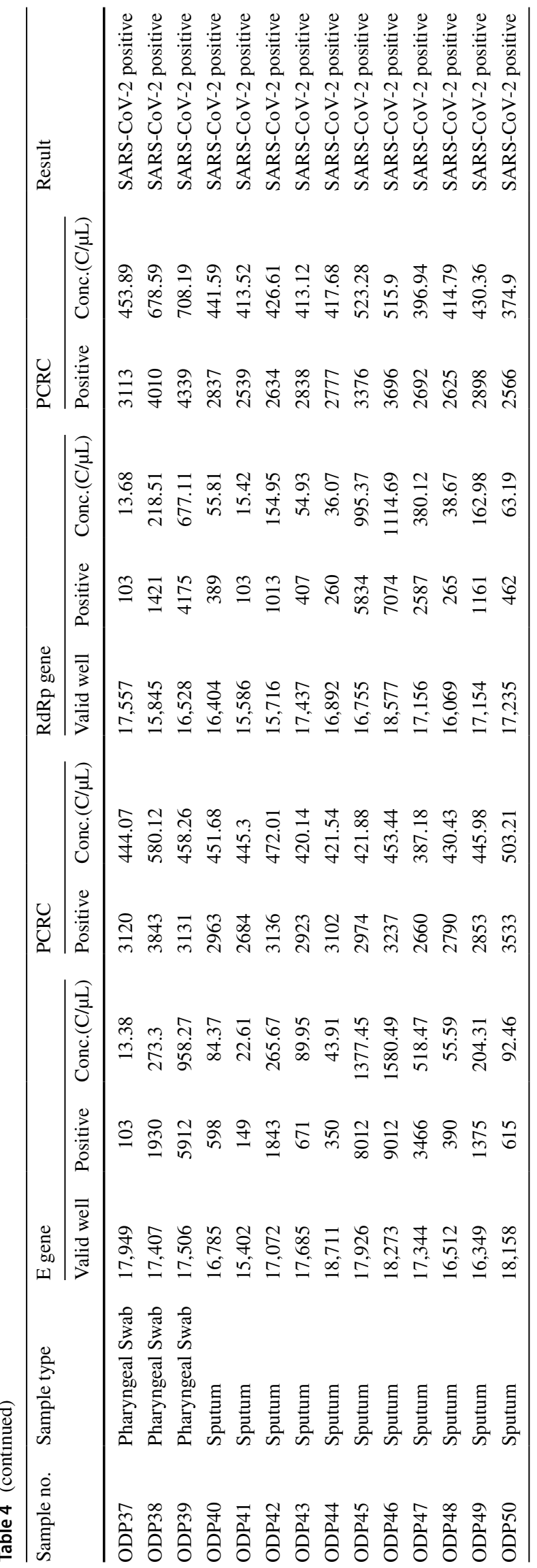

Cohen's Kappa Coefficient, the value was "Almost Perfect" with " 1 ".

In order to evaluate the detection capability between the two kits according to the extraction efficiency of viral RNA, a high concentration of COVID-19 positive sample (Ct value near 10) was prepared. The high concentration of COVID19 positive sample was spike-in treated with the negative patient sample, diluted, and then the dilutional linearity experiments were performed.

The correlation between the detection capability between the two kits was confirmed with the spike-in treatment of the negative patient sample on the high concentration of COVID-19 positive sample. The treated sample was diluted from $10^{-1}$ to $10^{-10}$ (Supplementary Table S4), and then the dilutional linearity experiments were performed. As shown in Table 5, the Allplex ${ }^{\mathrm{TM}}$ 2019-nCoV Assay kit result can confirm that COVID-19 was detected up to $10^{-6}$. On the other hand, the results of the Dr. PCR 20 K COVID19 Detection kit were capable of detecting COVID-19 up to $10^{-7}$ (Table 6). This indicates that the Dr. PCR $20 \mathrm{~K}$ COVID-19 detection kit was about 10 times higher than the Allplex ${ }^{\mathrm{TM}}$ 2019-nCoV Assay kit in the detection capability according to the extraction efficiency of viral RNA. In addition, the regression analysis results of each kit according to the dilution factor showed that the Allplex ${ }^{\mathrm{TM}} 2019-\mathrm{nCoV}$ Assay kit had an average of $R^{2}=0.9972$, and the Dr. PCR 20 K COVID-19 Detection kit was $\mathrm{R}^{2}=0.9948$, confirming very high detection reliability for both kits (Fig. 3). In summary, we represent that the diagnosis of COVID-19 using dPCR is advantageous compared to qRT-PCR in samples infected with infinitesimal amounts of SARS-CoV-2 in the early stages of infection.

\section{Correlation analysis of qRT-PCR and dPCR for RdRp gene and $E$ gene}

We performed correlation analysis on the detection levels of RdRp gene and $\mathrm{E}$ gene from diluted viral RNA extracted from qRT-PCR-based Allplex ${ }^{\mathrm{TM}}$ 2019-nCoV Assay kit and dPCR- based Dr. PCR 20 K COVID-19 Detection kit. As shown in Fig. 4, $\mathrm{R}^{2}$ was confirmed through regression analysis in which qRT-PCR was the Ct value and dPCR was the $\mathrm{C} / \mu \mathrm{L}$ value for each dilution factor extract. As a result, the $\mathrm{R}^{2}$ value was 0.994 in the RdRp gene and 0.9964 in the $\mathrm{E}$ gene, which means that the two experiments have a very high correlation for each gene.

\section{Conclusions}

In this study, Optolane's Dr. PCR 20 K COVID-19 Detection kit was compared with Seegene's Allplex ${ }^{\mathrm{TM}}$ 2019-nCoV Assay kit, a product that has already received the US FDA 
Table 5 qRT-PCR results with Allplex ${ }^{\mathrm{TM}}$ 2019-nCoV Assay kit of SARS-CoV-2 genes according to dilution factor

\begin{tabular}{llllr}
\hline Dilution factor & E gene & RdRp gene & N gene & PCRC \\
\hline Dilute(1 $\left(10^{-1}\right)$ & 16.07 & 17.16 & 18.76 & N/A \\
Dilute(2) $\left(10^{-2}\right)$ & 18.83 & 20.75 & 22.10 & 26.22 \\
Dilute(3 $\left(10^{-3}\right)$ & 22.67 & 24.23 & 25.41 & 24.31 \\
Dilute(4) $\left(10^{-4}\right)$ & 26.02 & 27.84 & 28.46 & 25.54 \\
Dilute(5 $\left(10^{-5}\right)$ & 28.41 & 30.64 & 30.89 & 24.79 \\
Dilute( $\left(10^{-6}\right)$ & 32.58 & 35.06 & 34.63 & 25.67 \\
Dilute(7) $\left(10^{-7}\right)$ & N/A & N/A & 37.86 & 25.08 \\
Dilute( $\left(10^{-8}\right)$ & N/A & N/A & 37.98 & 24.90 \\
Dilute( $\left(10^{-9}\right)$ & N/A & N/A & N/A & 24.56 \\
Dilute(10 $\left(10^{-10}\right)$ & N/A & N/A & N/A & 24.83 \\
\hline
\end{tabular}

EUA and the Korea MFDS EUA approval for clinical efficacy evaluation. As a result of testing the same COVID-19 diagnostic positive and negative samples, it was confirmed that the results of the dPCR-based Dr. PCR 20 K COVID-19 Detection kit and the results of qRT-PCR-based Allplex ${ }^{\mathrm{TM}}$ 2019-nCoV Assay kit were consistent. That is, it was confirmed that these two kits had high sensitivity and specificity in the evaluation of the capability to detect COVID-19 using SARS-CoV-2 viral nucleic acids extracted from sputum and nasopharyngeal smears. However, according to the dilutional linearity experiments results, the Dr. PCR $20 \mathrm{~K}$ COVID-19 Detection kit confirmed about ten times higher detection capability at a lower viral load than the Allplex ${ }^{\mathrm{TM}}$ 2019-nCoV Assay kit. Taken together, we confirmed that the detection of COVID-19 using LOAA dPCR is advantageous

Table 6 dPCR results with Dr. PCR 20 K COVID 19 Detection kit of SARS-CoV-2 genes according to dilution factor

\begin{tabular}{|c|c|c|c|c|}
\hline Dilution factor & RdRp gene & PCRC & E gene & PCRC \\
\hline Dilute $1\left(10^{-1}\right)$ & Above linear range & 778.15 & Above linear range & 414.67 \\
\hline Dilute(2) $\left(10^{-2}\right)$ & 9977.12 & 905.83 & 20000.72 & 455.95 \\
\hline Dilute(3) $\left(10^{-3}\right)$ & 933.68 & 490.65 & 1644.83 & 460.05 \\
\hline Dilute(4) $\left(10^{-4}\right)$ & 95.13 & 473.86 & 163.81 & 439.83 \\
\hline Dilute(5) $\left(10^{-5}\right)$ & 9.10 & 433.92 & 16.12 & 433.63 \\
\hline Dilute@ $\left(10^{-6}\right)$ & 1.09 & 454.22 & 1.09 & 913.64 \\
\hline Dilute $7\left(10^{-7}\right)$ & 0.26 & 445.99 & 0.28 & 399.05 \\
\hline Dilute $8\left(10^{-8}\right)$ & 0.00 & 426.27 & 0.00 & 455.74 \\
\hline Dilute $9\left(10^{-9}\right)$ & 0.00 & 421.84 & 0.00 & 413.96 \\
\hline Dilute(10 $\left(10^{-10}\right)$ & 0.00 & 451.08 & 0.00 & 460.07 \\
\hline
\end{tabular}

(A)

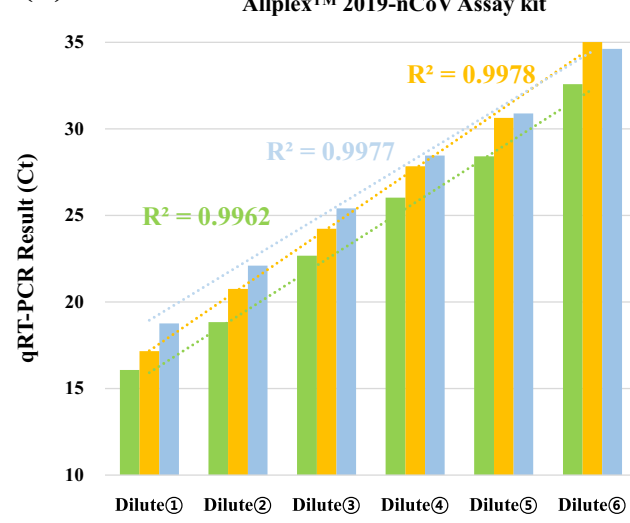

Fig. 3 The dilutional linearity experiments for the detection capability evaluation of each kit according to the dilution factor. A The dilutional linearity experiments using a qRT-PCR method with the Allplex ${ }^{\mathrm{TM}}$ 2019-nCoV Assay kit according to the dilution factor of
(B)
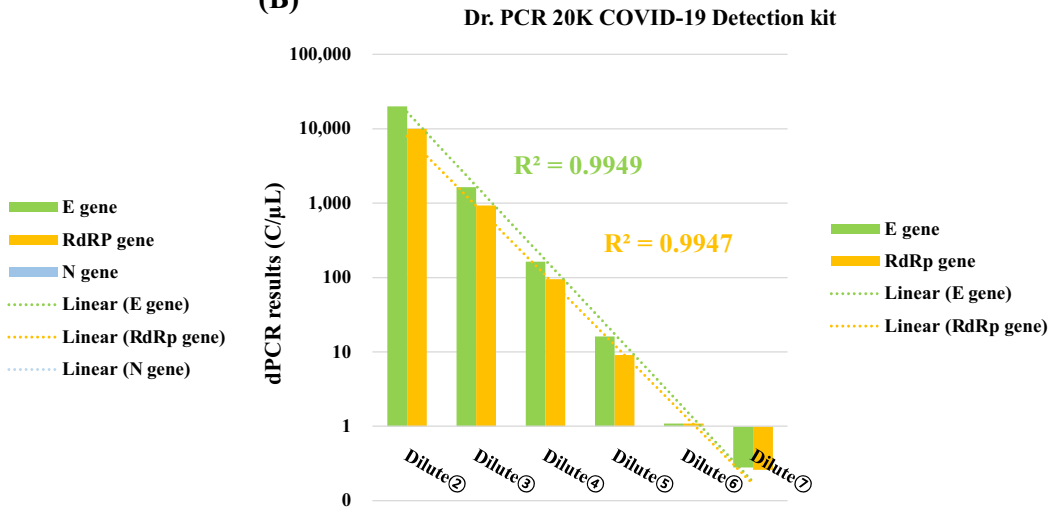

SARS-CoV-2. B The dilutional linearity experiments using a dPCR method with the Dr. PCR 20 K COVID-19 Detection kit according to the dilution factor of SARS-CoV-2 


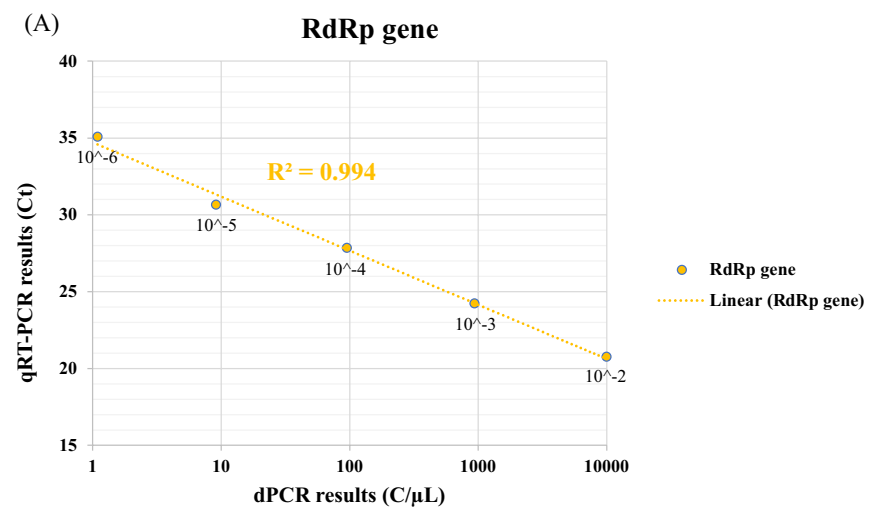

Fig. 4 Correlation analysis between dPCR and qRT-PCR results of SARS-CoV-2 genes according to dilution factors. A shows the correlation between $\mathrm{dPCR}$ and qRT-PCR results according to the dilution

compared to qRT-PCR in terms of relatively lower sample concentration, the small size of equipment, and low equipment price. Therefore, we propose that the use of LOAA dPCR can be expected for COVID-19 point-of-care testing (POCT) in confined spaces and where the immediate diagnosis is required.

Supplementary Information The online version contains supplementary material available at https://doi.org/10.1007/s13258-021-01162-4.

Acknowledgements The authors gratefully acknowledge Center for Bio-Medical Engineering Core Facility at Dankook University for providing critical reagents and equipment. This study has been done with the participation of undergraduate students working at DKU-Theragen institute for NGS analysis (DTiNa) of Dankook University. The research institute has been supported by the VIP system as a part of the University innovation Support Program 2021 of Dankook University.

\section{Declarations}

Conflict of interest Cherl-Joon Lee, Wonseok Shin, Seyoung Mun, Minjae Yu, Young-Bong Choi, Dong Hee Kim, and Kyudong Han declare that we have no conflict of interest.

Ethical approval All procedures performed in studies involving human participants were in accordance with the ethical standards of the institutional and/or national research committee.

\section{References}

Ambrosi C, Prezioso C, Checconi P, Scribano D, Sarshar M, Capannari M, Tomino C, Fini M, Garaci E, Palamara AT et al (2021) SARS-CoV-2: comparative analysis of different RNA extraction methods. J Virol Methods 287:114008

Cao L, Cui X, Hu J, Li Z, Choi JR, Yang Q, Lin M, Ying Hui L, Xu $F$ (2017) Advances in digital polymerase chain reaction (dPCR) and its emerging biomedical applications. Biosens Bioelectron 90:459-474

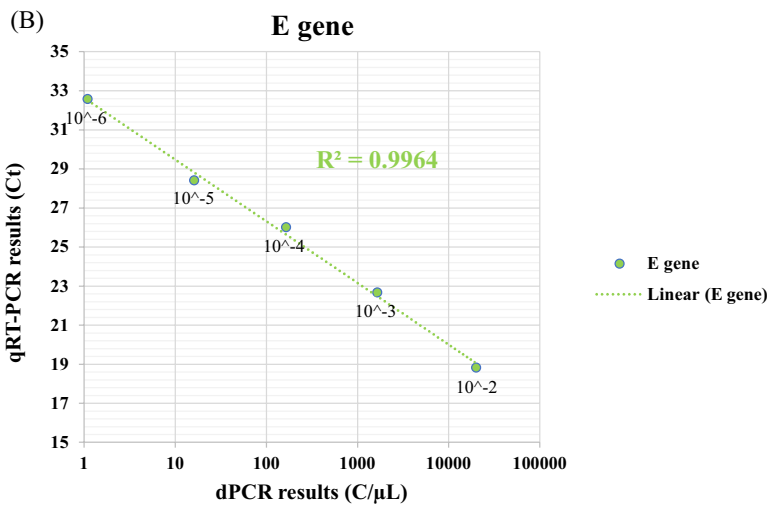

factor of the RdRp gene. B Shows the correlation between dPCR and qRT-PCR results according to the dilution factor of the E gene

Cascella M, Rajnik M, Aleem A, Dulebohn SC, Di Napoli R (2021) Features, evaluation, and treatment of Coronavirus (COVID-19). StatPearls, Treasure Island

Chung YS, Lee NJ, Woo SH, Kim JM, Kim HM, Jo HJ, Park YE, Han MG (2021) Validation of real-time RT-PCR for detection of SARS-CoV-2 in the early stages of the COVID-19 outbreak in the Republic of Korea. Sci Rep 11:14817

Czodrowski P (2014) Count on kappa. J Comput Aided Mol Des 28:1049-1055

Daly CH, Neupane B, Beyene J, Thabane L, Straus SE, Hamid JS (2019) Empirical evaluation of SUCRA-based treatment ranks in network meta-analysis: quantifying robustness using Cohen's kappa. Bmj Open 9:e024625

Dang Y, Liu N, Tan CAR, Feng YM, Yuan XX, Fan DD, Peng YK, Jin RH, Guo Y, Lou JL (2020) Comparison of qualitative and quantitative analyses of COVID-19 clinical samples. Clin Chim Acta 510:613-616

Dhamad AE, Rhida MAA (2020) COVID-19: molecular and serological detection methods. Peerj 8:e10180

Dong LH, Zhou JB, Niu CY, Wang QY, Pan Y, Sheng ST, Wang X, Zhang YZ, Yang JY, Liu MQ et al (2021) Highly accurate and sensitive diagnostic detection of SARS-CoV-2 by digital PCR. Talanta 224:121726

Freire-Paspuel B, Garcia-Bereguiain MA (2021) Analytical and clinical evaluation of "AccuPower SARS-CoV-2 Multiplex RT-PCR kit (Bioneer, South Korea)" and "Allplex 2019-nCoV Assay (Seegene, South Korea)" for SARS-CoV-2 RT-PCR diagnosis: Korean CDC EUA as a quality control proxy for developing countries. Front Cell Infect Microbiol 11:630552

Freppel W, Merindol N, Rallu F, Bergevin M (2020) Efficient SARSCoV-2 detection in unextracted oro-nasopharyngeal specimens by rRT-PCR with the Seegene Allplex (TM) 2019-nCoV assay. Virol J 17:196

Garg D, Srivastava AK, Dhamija RK (2020) Beyond fever, cough and dyspnea: the neurology of COVID-19. J Assoc Physicians India 68:62-66

Garg A, Ghoshal U, Patel SS, Singh DV, Arya AK, Vasanth S, Pandey A, Srivastava N (2021) Evaluation of seven commercial RT-PCR kits for COVID-19 testing in pooled clinical specimens. J Med Virol 93:2281-2286

Goudouris ES (2021) Laboratory diagnosis of COVID-19. J Pediatr (Rio J) 97:7-12 
Gupta N, Augustine S, Narayan T, O'Riordan A, Das A, Kumar D, Luong JHT, Malhotra BD (2021) Point-of-care PCR assays for COVID-19 detection. Biosensors (Basel) 11:141

Huergo MAC, Thanh NTK (2021) Current advances in the detection of COVID-19 and evaluation of the humoral response. Analyst 146:382-402

Inaba M, Higashimoto Y, Toyama Y, Horiguchi T, Hibino M, Iwata M, Imaizumi K, Doi Y (2021) Diagnostic accuracy of LAMP versus PCR over the course of SARS-CoV-2 infection. Int J Infect Dis 107:195-200

Kim KB, Choi H, Lee GD, Lee J, Lee S, Kim Y, Cho SY, Lee DG, Kim M (2021) Analytical and clinical performance of droplet digital PCR in the detection and quantification of SARS-CoV-2. Mol Diagn Ther 25:617-628

Kumar A, Singh R, Kaur J, Pandey S, Sharma V, Thakur L, Sati S, Mani S, Asthana S, Sharma TK et al (2021) Wuhan to World: the COVID-19 pandemic. Front Cell Infect Microbiol 11:596201

Lai CC, Wang CY, Ko WC, Hsueh PR (2021) In vitro diagnostics of coronavirus disease 2019: technologies and application. J Microbiol Immunol Infect 54:164-174

Lee CY, Degani I, Cheong J, Lee JH, Choi HJ, Cheon J, Lee H (2021) Fluorescence polarization system for rapid COVID-19 diagnosis. Biosens Bioelectron 178:113049

Lin L, Carlquist J, Sinclair W, Hall T, Lopansri BK, Bennett ST (2021) Experience with false-positive test results on the TaqPath realtime reverse transcription-polymerase chain reaction Coronavirus Disease 2019 (COVID-19) testing platform. Arch Pathol Lab Med 145:259-261

Murphy J, Bustin SA (2009) Reliability of real-time reverse-transcription PCR in clinical diagnostics: gold standard or substandard? Expert Rev Mol Diagn 9:187-197

Padoan A, Cosma C, Sciacovelli L, Faggian D, Plebani M (2020) Analytical performances of a chemiluminescence immunoassay for SARS-CoV-2 IgM/IgG and antibody kinetics. Clin Chem Lab Med 58:1081-1088

Park J, Chung E (2021) Learning from past pandemic governance: early response and public-private partnerships in testing of COVID-19 in South Korea. World Dev 137:105198

Peck KR (2020) Early diagnosis and rapid isolation: response to COVID-19 outbreak in Korea. Clin Microbiol Infect 26:805-807
Russo A, Minichini C, Starace M, Astorri R, Calo F, Coppola N, Grp VC- (2020) Current status of laboratory diagnosis for COVID-19: a narrative review. Infect Drug Resist 13:2657-2665

Seegene (2021) AllplexTM 2019-nCoV Assay v 2.2 (Cat no. RP10250X/ RP10252W) instructions for use. https://www.fda. gov/media/137178/download. Accessed 15 Apr 2021

Sung H, Roh KH, Hong KH, Seong MW, Ryoo N, Kim HS, Lee J, Kim SY, Yoo S, Kim MN et al (2020) COVID-19 molecular testing in Korea: practical essentials and answers from experts based on experiences of emergency use authorization assays. Ann Lab Med 40:439-447

Syal K (2021) Guidelines on newly identified limitations of diagnostic tools for COVID-19 and consequences. J Med Virol 93:1837-1842

Udugama B, Kadhiresan P, Kozlowski HN, Malekjahani A, Osborne M, Li VYC, Chen HM, Mubareka S, Gubbay JB, Chan WCW (2020) Diagnosing COVID-19: the disease and tools for detection. Acs Nano 14:3822-3835

van Stralen KJ, Stel VS, Reitsma JB, Dekker FW, Zoccali C, Jager KJ (2009) Diagnostic methods I: sensitivity, specificity, and other measures of accuracy. Kidney Int 75:1257-1263

Verhaegen B, De Reu K, De Zutter L, Verstraete K, Heyndrickx M, Van Coillie E (2016) Comparison of droplet digital PCR and qPCR for the quantification of Shiga toxin-producing Escherichia coli in Bovine Feces. Toxins 8:157

Watson J, Whiting PF, Brush JE (2020) Interpreting a covid-19 test result. BMJ 369:m1808

Xu M, Wang D, Wang HY, Zhang XM, Liang T, Dai JY, Li M, Zhang JH, Zhang K, Xu DK et al (2020) COVID-19 diagnostic testing: technology perspective. Clin Transl Med 10:e158

Zhang L, Zhu F, Xie L, Wang C, Wang J, Chen R, Jia P, Guan HQ, Peng L, Chen Y et al (2020) Clinical characteristics of COVID19-infected cancer patients: a retrospective case study in three hospitals within Wuhan, China. Ann Oncol 31:894-901

Publisher's Note Springer Nature remains neutral with regard to jurisdictional claims in published maps and institutional affiliations. 